\title{
ESTUDO DO POLIMORFISMO GENÉTICO NO GENE p53 (CÓDON 72) EM CÂNCER COLORRETAL
}

\author{
Jacqueline Miranda de LIMA, Patrícia Valéria Pereira SERAFIM, \\ Ismael Dale Cotrim Guerreiro da SILVA e Nora Manoukian FORONES
}

RESUMO - Racional - Polimorfismos genéticos são variações genéticas que podem ocorrer em seqüências codificadoras e nãocodificadoras, levando a alterações qualitativas e/ou quantitativas das proteínas em questão. O p53 é o gene mais comumente alterado no câncer humano. O polimorfismo desse gene no códon 72 ocorre por substituição de uma base e tem sido associado a maior risco de câncer. Objetivo - Determinar a possível associação entre o polimorfismo no códon 72 (72 arginina/prolina) do gene p53 e câncer colorretal. Casuística e Métodos - Foram avaliados em 100 pacientes com câncer colorretal e em 100 indivíduos sem câncer, pareados quanto ao sexo idade, o hábito de fumar, o etilismo e no grupo caso o estádio, o grau de diferenciação e a evolução da doença. O genótipo (72 arginina/prolina) foi determinado por PCR, utilizando-se primers (seqüências de nucleotídeos) específicos. Resultados - O genótipo homozigoto arginina/arginina foi prevalente em 56\% no grupo controle e em 58\% no grupo caso. Não se observou diferença entre os dois grupos. No estádio IV este genótipo foi mais freqüente quando comparado ao estádio I ( $80 \%$ versus 14\%). Não se observou diferença entre as variações do genótipo e fumo, álcool, evolução clínica ou grau de diferenciação. Conclusão - A prevalência do genótipo arginina/arginina foi a mais freqüente nos dois grupos. Não foi encontrada correlação entre maior risco de câncer e o polimorfismo no códon 72 prolina/arginina do gene p53. Apesar do pequeno número de doentes com câncer em estádio avançado (IV), estes tiveram maior prevalência do genótipo arginina/arginina.

DESCRITORES - Polimorfismo (genética). Genes p53. Neoplasias colorretais. Prognóstico.

\section{INTRODUÇÃO}

Alterações genéticas têm papel decisivo no aparecimento de várias neoplasias humanas ${ }^{(2)}$. Na maioria, essas alterações genéticas ocorrem em uma única célula somática, que então se divide e continua se desenvolvendo até formar um câncer. Mais raramente, quando a neoplasia maligna ocorre como parte de uma síndrome de câncer hereditário, as alterações iniciais são herdadas por meio de linhagem germinativa e, portanto estão presentes em todas as células do organismo ${ }^{(15)}$.

Mutações e polimorfismos são duas alterações genéticas freqüentes. As mutações são representadas pela substituição de bases, alterações na organização ou no tamanho das seqüências, incorporação do DNA extracromossômico e alterações anafásicas ou da citocinese. Essas alterações estão associadas à freqüência de alelos heterozigotos presentes em menos de $2 \%$ da população ${ }^{(1)}$. Os polimorfismos genéticos são variações na seqüência de DNA que podem criar ou destruir sítios de reconhecimento de enzimas de restrição e parecem estar associados a apenas uma base. A freqüência de alelos heterozigotos para o polimorfismo genético ocorre em mais de $2 \%$ da população. Algumas dessas alterações ocorrerão em seqüências não codificadoras do gene, que na maioria dos casos não terão efeito em suas funções; outras ocorrerão em seqüências codificadoras, levando à produção de proteínas defeituosas. Deste modo, em alguns casos o polimorfismo genético pode aumentar a suscetibilidade ao câncer ${ }^{(11)}$.

Mundialmente, o câncer colorretal foi a quarta neoplasia mais incidente tanto no sexo masculino, quanto no feminino. A sobrevida global em 5 anos é de $60 \%$ e não são observadas diferenças significativas entre países desenvolvidos e em desenvolvimento. No Brasil, o câncer de cólon e reto é a quinta causa de morte no sexo masculino e a terceira no sexo feminino ${ }^{(5)}$, tendo-se observado aumento consistente de suas taxas de mortalidade ao longo das últimas décadas.

Setor de Oncologia, Disciplina de Gastroenterologia, Universidade Federal de São Paulo, Escola Paulista de Medicina, São Paulo, SP. Estudo financiado pela da Fundação de Amparo à Pesquisa do Estado de São Paulo - FAPESP, São Paulo, SP.

Endereço para correspondência: Dra. Nora Manoukian Forones - Disciplina de Gastroenterologia Clínica - Rua Botucatu, 740 - $2^{\circ}$ andar - Vila Clementino - $04023-900$ - São Paulo, SP 
O câncer colorretal divide-se basicamente em dois grandes grupos de acordo com a história familiar: o esporádico, que corresponde a $85 \%$ do total das neoplasias malignas colorretais, e o hereditário, que compreende aproximadamente $15 \%$ do total ${ }^{(3)}$, estando subdividido em: síndrome da polipose adenomatosa familiar (PAF) e câncer colorretal hereditário sem polipose (HNPCC).

Apesar de serem síndromes genéticas herdadas por várias gerações de uma família, os mecanismos de carcinogênese envolvem a herança genética e uma seqüência elaborada de outras alterações genéticas somáticas que se juntam ao fator herdado para propiciar condições favoráveis à carcinogênese $\mathrm{e}^{(12)}$.

No câncer colorretal há duas vias genéticas da carcinogênese: via de instabilidade cromossômica, que ocorre na PAF, onde o paciente herda uma mutação do gene supressor tumoral APC (polipose adenomatosa colônica), e via de hipermutabilidade do DNA, que ocorre no HNPCC em que a alteração genética herdada é a inativação de um dos alelos dos genes envolvidos no reparo do DNA (genes hMSH2 e hMLH1). Entretanto, outros genes estão envolvidos na carcinogênese colorretal, como: gene $\mathrm{K}$-ras, gene DCC, gene $\mathrm{p} 53$, etc ${ }^{(25)}$.

A perda do gene p53 é crucial para a transformação do adenoma colorretal em carcinoma ${ }^{(6)}$. Freqüentemente, está inativo em grande variedade de tumores humanos, incluindo leucemias, linfomas, tumores cerebrais e carcinomas de muitos tecidos, como mama, pulmão e cólon ${ }^{(14)}$.

Os genes supressores de tumor estão envolvidos no controle de pontos estratégicos da cadeia de eventos que controla o crescimento e a diferenciação celular. Esses genes precisam ter dois alelos alterados para induzir o câncer. A perda de uma cópia do gene decorre de mutação, enquanto a segunda cópia é perdida por deleção do outro alelo, o que se denomina perda de heterozigosidade. A perda de um alelo pode ser herdada ou adquirida. $\mathrm{O}$ indivíduo heterozigoto para um gene supressor de tumor não tem neoplasia, mas apresenta risco maior de desenvolver um tumor ${ }^{(27)}$.

O p53 é um gene supressor tumoral clássico, que age na regulação do desenvolvimento e do crescimento celular ${ }^{(21)}$. Está localizado no lócus $17 \mathrm{p} 13$, codificando uma proteína de $53 \mathrm{kDa} \mathrm{e}$ 393, aminoácidos que têm a característica de ser expressa quando o DNA sofre algum tipo de dano, onde a proteína p53 se liga ao local danificado do DNA e interrompe as células na fase $\mathrm{G}$ do ciclo celular ${ }^{(9)}$, ativando mecanismos de reparo do DNA ou mesmo de apoptose ${ }^{(20)}$.

A proteína p53 foi primeiramente identificada em 1979 em estudo com o vírus "simian 40 (SV40)" e o antígeno T. Esta proteína tem elevado nível de expressão em tumores e em células transformadas ${ }^{(7)}$.

A linhagem germinativa da $\mathrm{p} 53$ tem sido relacionada à hereditariedade para predisposição do câncer (síndrome de LiFraumeri). O aumento da quantidade dessa proteína celular tem sido associado à interrupção do ciclo celular e a programação da morte da célula (apoptose). Na célula, cujo material genético está danificado, a p53 ativa a produção da proteína p21, que interage com o receptor de ciclina dependente de quinases 2 (cdk2), que estimula a divisão celular. Quando a p21 forma complexos com cdk2, a célula é impedida de avançar para o próximo estágio da divisão celular. Quando mutada, a p53 deixa de ativar a produção de p21, tornando a divisão celular processo descontrolado e induzindo a formação de tumores ${ }^{(26)}$.

Além da mutação, o polimorfismo do gene supressor de tumor p53, no códon 72 , tem sido investigado extensivamente para associação com vários cânceres em todo o mundo ${ }^{(8)}$. $\mathrm{O}$ códon 72 codifica um aminoácido arginina (CGC; Arg72) e um prolina (CCC; Pro72), correspondendo a arginina/prolina (Arg/Pro) ${ }^{(23)}$. O polimorfismo ocorre por simples substituição de uma base no códon que resulta em alteração estrutural da proteína $\mathrm{p} 53^{(24)}$. Vários autores têm demonstrado que a presença de $\mathrm{Arg} / \mathrm{Arg}$ confere maior risco de desenvolvimento de tumores, como em cânceres de bexiga, cérvix uterino ${ }^{(22)}$, mama ${ }^{(16)}$, pulmão $^{(17)}$, etc. Entretanto, no câncer colorretal não há uma associação clara com este polimorfismo e aumento do risco de câncer ${ }^{(10)}$.

\section{Objetivos}

1. Determinar a prevalência de polimorfismos no códon 72 do gene p53 em pacientes com neoplasia colorretal em relação a um grupo controle;

2. relacionar a presença desse polimorfismo com hábitos de vida, estádio, grau de diferenciação e evolução clínica da doença.

\section{CASUÍSTICA E MÉTODOS}

Foram estudados 100 pacientes com câncer colorretal, atendidos no setor de Oncologia da Disciplina de Gastroenterologia da Universidade Federal de São Paulo, Escola Paulista de Medicina, com idades entre 20 e 80 anos, e com diferentes prognósticos. Cem indivíduos sem câncer, que procuram o ambulatório para tratamento de dispepsia foram pareados quanto ao sexo e idade (com diferença de até 5 anos), constituíram o grupo controle. Os grupos foram submetidos a entrevista e coleta de sangue venoso. O estudo foi aprovado pelo Comitê de Ética da instituição e os participantes assinaram termo de consentimento.

A entrevista foi realizada no local de internação ou de atendimento do paciente e teve como tempo máximo 5 minutos de duração. Os dados requeridos na pesquisa foram: registro hospitalar, nome, data de nascimento, idade, sexo, raça, endereço, diagnóstico, estádio, história familiar e hábitos de vida (tabagismo e etilismo) e situação no momento da investigação (sem doença ou com recidiva).

A coleta de sangue foi realizada em veia periférica em tubos a vácuo contendo anticoagulante (EDTA). Os tubos foram centrifugados durante 15 minutos numa velocidade de $4.000 \mathrm{rpm}$, para separação em plasma, leucócitos e hemácias. As células nucleadas (leucócitos) foram depositadas em tubos tipo coneificados para $1,5 \mu \mathrm{L}$ para posterior procedimento de extração de DNA ou armazenamento em freezer a $-80^{\circ} \mathrm{C}$, até o momento da extração.

A extração de DNA foi realizada através de kit comercial específico para extração em sangue (Genomic Blood DNA Purification Kit, Amersham Biosciences), conforme procedimento do fabricante.

Foram utilizados dois primers distintos, descritos em estudos semelhantes ${ }^{(2)}$ : um para arginina e outro para prolina (Tabela 1). 
Foram utilizados: $10 \mu \mathrm{L}$ de Master Mix (PCR Master Mix, 2.0x, Promega), $1 \mu \mathrm{L}$ de primer de arginina ou prolina a (10pM/ul), $9 \mu \mathrm{L}$ de água sem nucleases (Nuclease-Free Water, Promega) e $3 \mu \mathrm{L}$ de DNA genômico, totalizando $25 \mu \mathrm{L}$ por reação.

TABELA 1 - Primers para avaliação do polimorfismo

\begin{tabular}{lccc}
\hline & Senso 5’3' & Anti-senso 5'3' & PB \\
\hline Arg & TCC CCC TTG CCG TCC CAA' & CTG GTG CAG GGG CCA CGC & 141 \\
Pro & GCC AGA GGC TGC TCC CCC & CGT GCA AGT CAC AGA CTT & 177 \\
\hline Arg: arginina; Pro: prolina; PB: pares de bases & &
\end{tabular}

$\mathrm{Na}$ amplificação dos primers para detecção do alelo arginina foram determinadas as seguintes condições de temperaturas e tempos: $94^{\circ} \mathrm{C}$ durante 3 minutos para denaturação, $94^{\circ} \mathrm{C}, 60^{\circ} \mathrm{C}$ e $72^{\circ} \mathrm{C}$ durante 30 segundos cada, com 35 ciclos, para anelamento e extensão da fita, e $72^{\circ} \mathrm{C}$ durante 5 minutos para o término da reação. Para detecção do alelo prolina foram determinadas as mesmas condições de tempos e temperaturas, com exceção da temperatura de anelamento adaptada a $57^{\circ} \mathrm{C}$.

Os produtos amplificados foram submetidos a separação por eletroforese em gel de agarose (Agarose NA, Amersham Biosciences) a $2 \%$, com marcador de peso molecular de 100pb (DNA Ladder, Promega), sob 103 volts e foram fotodocumentados através do sistema "Kodak Digital Science 1D".

\section{Análise estatística}

Para estudar a associação entre a doença e as variáveis categóricas analisadas, empregou-se o teste de qui-quadrado de Pearson. Para a variável idade, foi usado o teste $t$ de Student para amostras independentes. Para estudar a associação entre o intervalo livre de doença e as demais variáveis consideradas no estudo, empregou-se o modelo de riscos proporcionais de Cox.

\section{RESULTADOS}

Entre os indivíduos do grupo controle e do grupo caso, 53 eram do sexo masculino. A média de idades foi de 60,8 anos no grupo controle e de 62,8 no grupo caso. Quanto à raça, os hábitos de vida como etilismo e tabagismo, a presença de história familiar de câncer entre grupo controle e do grupo caso, estão referidos na Tabela 2. Não se observou diferença estatística entre os dois grupos quanto à idade, etilismo e tabagismo.

$\mathrm{O}$ fragmento amplificado com primer para o alelo arginina, observado no gel de agarose representa a presença desse aminoácido no códon 72 do cromossomo 17. Da mesma maneira, a presença do fragmento amplificado com o primer do alelo prolina, também observado em gel de agarose, representa a presença desse aminoácido na mesma região cromossômica.

A amostra que amplificou para os dois alelos é considerada heterozigota arginina/prolina (Figura 1). A amostra que amplificou apenas para o alelo arginina é considerada homozigota arginina (Figura 2) e a que amplificou apenas para prolina é considerada homozigota prolina (Figura 3).

O genótipo homozigoto arginina, no gene 53 , códon 72 , foi observado em 56 pacientes com câncer colorretal, homozigoto prolina em 6 e o genótipo heterozigoto em 38. Entre os indivíduos do grupo controle, a variação genética foi de 58 indivíduos com
TABELA 2 - Correlação entre os grupos com câncer e controle

\begin{tabular}{lccc}
\hline & Paciente & Controle & $P$ \\
\hline Sexo & 47 & 47 & 1,00 \\
feminino & 53 & 53 & \\
masculino & & & \\
Raça & 71 & 75 & 0,92 \\
branca & 29 & 29 & \\
negra & & & \\
Fumante & 56 & 47 & 0,26 \\
sim & 44 & 53 & \\
não & & & \\
Etilista & 51 & 59 & 0,32 \\
sim & 49 & 41 & \\
não & & & \\
História na família & 8 & 1 & 0,04 \\
com & 92 & 99 & 0,98 \\
sem & & 58 & \\
Genótipo & 56 & 36 & \\
arg/arg & 38 & 6 & \\
arg/pro \\
pro/pro
\end{tabular}

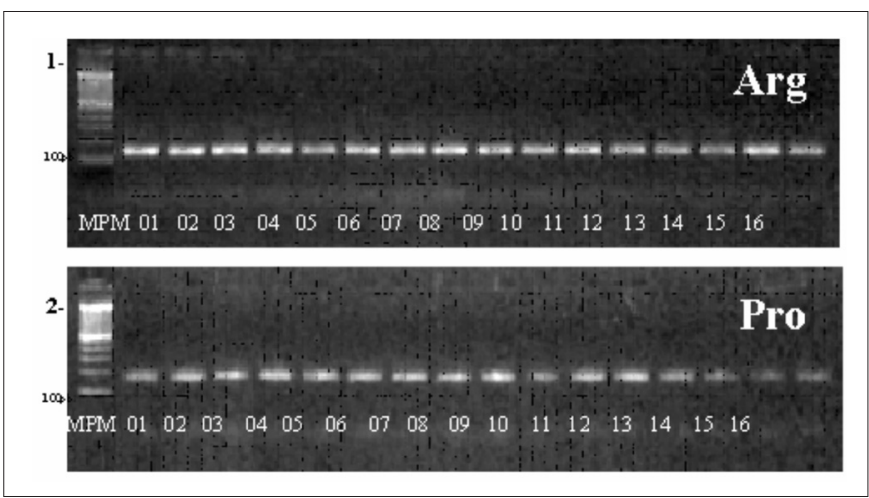

FIGURA 1 - Eletroforese de amostras de pacientes heterozigotos (Arg/ Pro). 1. Gel de agarose com amostras amplificadas para o alelo arginina $(141 \mathrm{pb}) .2$. Gel de agarose com amostras amplificadas para o alelo prolina $(177 \mathrm{pb})$

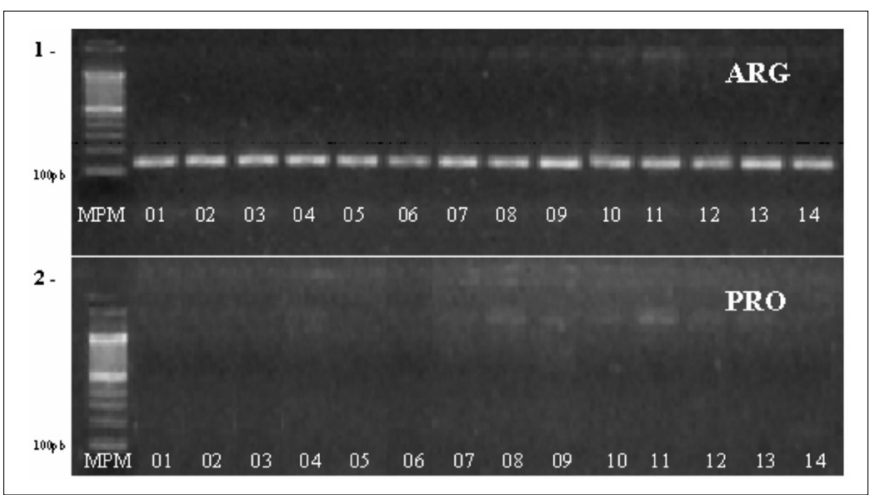

FIGURA 2 - Eletroforese de amostras de pacientes homozigotos arginina. 1. Gel de agarose com amostras amplificadas para o alelo arginina (141pb). 2. Gel de agarose sem amplificação para o alelo prolina 


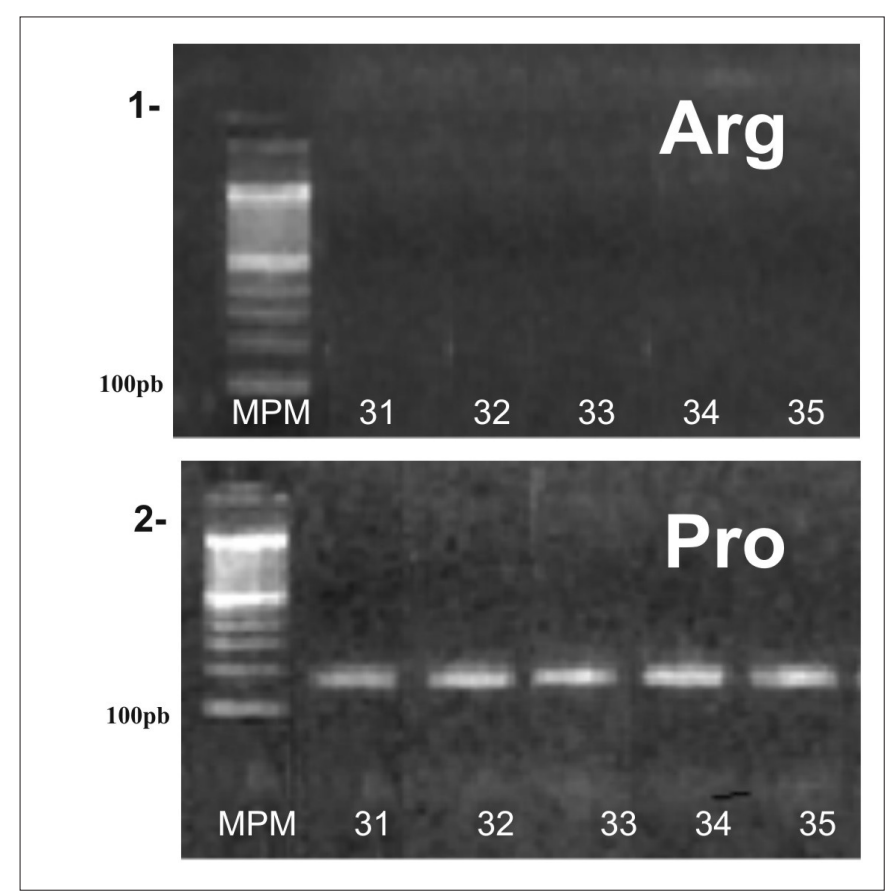

FIGURA 3 - Eletroforese de amostras de pacientes homozigotos prolina. 1. Gel de agarose sem amplificação para o alelo arginina. 2. Gel de agarose com amostras amplificadas para o alelo prolina $(177 \mathrm{pb})$

TABELA 3 - Características dos pacientes com CCR e as variações genéticas

\begin{tabular}{|c|c|c|c|c|c|}
\hline & Câncer & $\begin{array}{c}\text { Pro/Pro } \\
\text { n }(\%)\end{array}$ & $\begin{array}{c}\text { Arg/Pro } \\
\text { n }(\%)\end{array}$ & $\begin{array}{c}\text { Arg/Arg } \\
\text { n }(\%)\end{array}$ & $P$ \\
\hline \multicolumn{6}{|l|}{ Sexo } \\
\hline masculino & 47 & $5(10,6)$ & $14(29,8)$ & $25(53,2)$ & 0,10 \\
\hline feminino & 53 & $1(1,9)$ & $24(45,3)$ & $31(58,5)$ & \\
\hline \multicolumn{6}{|l|}{ Raça } \\
\hline branca & 71 & $4(0,59)$ & $25(32,89)$ & $42(59,15)$ & 0,93 \\
\hline negra & 26 & $2(7,69)$ & $11(42,30)$ & $16(61,53)$ & \\
\hline \multicolumn{6}{|l|}{ Recurrência } \\
\hline com doença & 41 & $2(4,9)$ & $14(34,1)$ & $25(60,9)$ & 0,70 \\
\hline sem doença & 59 & $4(6,8)$ & $24(40,7)$ & $31(56,4)$ & \\
\hline \multicolumn{6}{|l|}{ Estádio } \\
\hline I & 7 & $1(14,3)$ & $5(71,4)$ & $1(14,3)$ & 0,14 \\
\hline II & 33 & 0 & $12(36,4)$ & $21(63,6)$ & \\
\hline III & 55 & $5(9,1)$ & $20(36,4)$ & $30(54,5)$ & \\
\hline IV & 5 & 0 & $1(20,0)$ & $4(80,0)$ & \\
\hline \multicolumn{6}{|l|}{ Diferenciação } \\
\hline 1 & 50 & $4(8,0)$ & $19(38,0)$ & $27(54,0)$ & 0,43 \\
\hline 2 & 43 & $1(2,3)$ & $16(37,2)$ & $26(60,5)$ & \\
\hline 3 & 4 & 0 & $2(50,0)$ & $2(50,0)$ & \\
\hline 4 & 3 & $1(33,3)$ & $1(33,3)$ & $1(33,3)$ & \\
\hline \multicolumn{6}{|l|}{ Tabagismo } \\
\hline fumantes & 56 & $3(5,3)$ & $25(44,6)$ & $28(50,0)$ & 0,30 \\
\hline não-fumantes & 44 & $3(6,8)$ & $13(29,5)$ & $28(63,6)$ & \\
\hline \multicolumn{6}{|l|}{ Etilismo } \\
\hline $\operatorname{sim}$ & 51 & $4(7,8 \%)$ & $22(43,1)$ & $25(49,0)$ & 0,83 \\
\hline não & 49 & $2(4,1 \%)$ & $21(42,8)$ & $26(53,0)$ & \\
\hline
\end{tabular}

genótipo homozigoto arginina, 36 heterozigoto e 6 homozigoto prolina (Tabela 2).

A freqüência de variações genéticas correlacionadas ao sexo, raça, estádio clínico, grau de diferenciação, tabagismo e etilismo está representada na Tabela 3 para o grupo com câncer colorretal e na Tabela 4 para o grupo controle. Não se observaram diferenças estatísticas entre as variações genéticas e a raça, os hábitos de vida, o grau de diferenciação (Tabelas $3,4)$, ou recurrência da doença (Figura 4).

Embora o número de doentes estádio I e IV seja pequeno, observou-se no estádio I maior número de doentes com genótipo arg/pro $(71,4 \%)$ e no estádio IV o inverso, maior número arg/arg (80\%).

\section{DISCUSSÃO}

Grande variedade de alterações celulares que podem culminar no desenvolvimento de um tumor, vem sendo estudada em todo o mundo. A cada ano, inúmeras pesquisas são publicadas com o objetivo principal de elucidar as possíveis variações de cada componente celular (genes, proteínas, aminoácidos, enzimas etc),

TABELA 4 - Características dos indivíduos do grupo controle e variações genéticas

\begin{tabular}{lccccc}
\hline & Controle & $\begin{array}{c}\text { Pro/Pro } \\
\mathbf{n}(\%)\end{array}$ & $\begin{array}{c}\text { Arg/Pro } \\
\mathbf{n}(\%)\end{array}$ & $\begin{array}{c}\text { Arg/Arg } \\
\mathbf{n}(\%)\end{array}$ & $\boldsymbol{P}$ \\
\hline $\begin{array}{l}\text { Sexo } \\
\text { feminino }\end{array}$ & 47 & $5(10,6)$ & $15(31,9)$ & $27(57,4)$ & 0,17 \\
masculino & 53 & $1(1,8)$ & $21(39,6)$ & $31(58,5)$ & \\
$\begin{array}{l}\text { Tabagismo } \\
\text { fumantes }\end{array}$ & 47 & $3(6,4)$ & $15(31,9)$ & $29(61,7)$ & 0,72 \\
não-fumantes & 53 & $3(5,7)$ & $21(39,6)$ & $29(54,7)$ & \\
Etilismo & & & & & \\
sim & 59 & $4(6,8)$ & $22(37,3)$ & $25(42,3)$ & 0,79 \\
não & 41 & $3(7,3)$ & $15(36,6)$ & $23(56,1)$ & \\
\hline
\end{tabular}

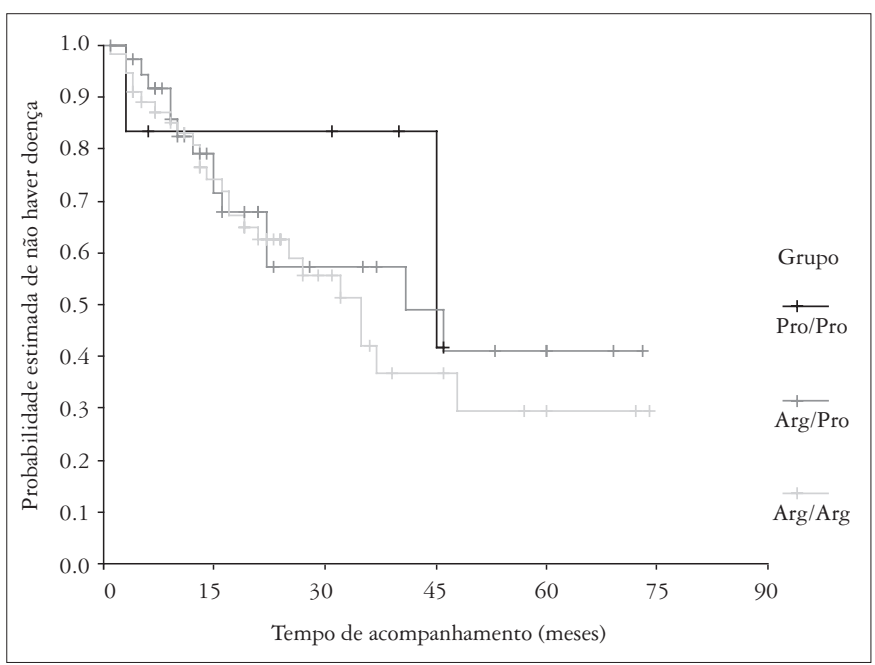

FIGURA 4 - Tempo livre de recurrência para cada genótipo estudado, segundo o modelo de riscos proporcionais de Cox. $P>0,05$ 
que podem atuar na transformação de uma célula normal em célula neoplásica e na sua progressão em diferentes tipos de tecidos. As alterações genéticas, como as diferentes formas de mutações e alguns polimorfismos genéticos, podem acometer qualquer região da seqüência de DNA e são os principais alvos destes estudos.

O polimorfismo no códon 72, prolina (pro) ou arginina (arg) está envolvido na habilidade do p53 em interagir com as proteínas celulares. Possivelmente este polimorfismo altera a conformação da proteína p53 alterada que se une a uma proteína denominada p73, impedindo a sua atividade em induzir a apoptose ${ }^{(13)}$. A p53 mutada teria maior ação sobre a p73 quando o polimorfismo no códon 72 codifica arginina ao invés de prolina ${ }^{(13)}$. Portanto, este polimorfismo arginina pode alterar o comportamento da p53 mutada. Esta diferença na atividade da p53 mutada fez com que a freqüência do polimorfismo genético no códon 72 do gene p53 fosse estudada por diversos pesquisadores nos últimos anos ${ }^{(4,10,13,17,19,22)}$.

SOULIZTIS et al. ${ }^{(22)}$, realizaram um estudo para determinar a associação desse polimorfismo em pacientes com câncer de bexiga. A investigação foi realizada em 50 amostras de sangue e de tumor comparada a 50 amostras de sangue de pacientes controles. Esses autores observaram que $60 \%$ dos pacientes com câncer de bexiga apresentaram genótipo homozigoto arginina, enquanto se observou este fato em apenas $24 \%$ da população controle. Ao contrário, a freqüência do genótipo heterozigoto (arginina/prolina) foi de 36\% nos pacientes e de $64,7 \%$ no grupo controle, demonstrando que a presença do genótipo Arg/Arg pode estar associada ao desenvolvimento do tumor de bexiga.

PAPADAKIS et al. ${ }^{(17)}$ também realizaram estudo para avaliar a associação deste polimorfismo no câncer de pulmão avançado. Em 54 pacientes com câncer de pulmão e 99 indivíduos do grupo controle, submetidos a coleta de lavado brônquico e sangue periférico, os pesquisadores encontraram freqüência do genótipo homozigoto arginina em 50\% dos pacientes com câncer de pulmão avançado e $24 \%$ da população controle. No entanto, o genótipo arg/pro foi semelhante entre os dois grupos, sendo de $50 \%$ nos pacientes e $64 \%$ na população controle.

SAYHAN et al. ${ }^{(18)}$ estudaram essas variações genéticas em câncer colorretal e associaram os resultados à infecção por papiloma herpes vírus. Esses pesquisadores utilizaram 67 amostras de ressecção cirúrgica de pacientes com câncer e 76 indivíduos sem evidências de câncer ou doenças gastrointestinais.
Entre os pacientes com câncer, 38,8\% apresentaram genótipo homozigoto arginina, 44,8\% genótipo heterozigoto e $16,4 \%$ homozigoto prolina. No grupo controle os resultados foram $27,6 \%, 56,5 \%$ e $15,85 \%$, respectivamente. Essas diferenças não foram estatisticamente significantes.

Estudo recentemente publicado, realizado por GEMIGNANI et al. ${ }^{(4)}$, também analisou o risco de desenvolvimento do câncer colorretal e o polimorfismo no referido gene. Em 374 casos e 322 controles, os autores observaram homozigose arginina em $54 \%$, heterozigose em $36 \%$ e homozigose para prolina em 5\% dos doentes com câncer. Não encontraram diferenças entre a freqüência do genótipo homozigoto arginina e heterozigoto entre os grupos.

A freqüência de homozigose descrita neste estudo foi semelhante à que se observou (56\% arginina e 6\% prolina), sendo que também não se observou diferença entre os grupos. Em ambos os grupos houve maior prevalência do genótipo homozigoto para arginina. No estádio IV este genótipo foi freqüente em $80 \%$ dos casos, ao contrário do estádio I que foi $14,3 \%$. Este maior percentual de arg/arg em doentes avançados também foi descrito por SCHNEIDER-STOCK et al. ${ }^{(19)}$.

A correlação entre sexo, grau de diferenciação e evolução não mostrou diferença estatística significante. Não se encontrou relato entre associação de fumo ou álcool e alterações do genótipo arg/pro. Neste estudo não se observou variação entre estes hábitos e este polimorfismo.

Ao contrário do observado para outros tumores, no câncer colorretal provavelmente não existe diferença entre o risco de desenvolvê-lo e a presença do genótipo homozigoto arginina ou heterozigoto.

Pode-se concluir que: a prevalência de genótipo homozigoto arginina foi observada em pouco mais da metade dos indivíduos, independente da presença ou não de câncer, sendo portanto, o genótipo mais freqüente. O polimorfismo do gene p53 (códon 72) não se associou com maior risco de desenvolvimento de câncer colorretal na população estudada. Embora o número de doentes tenha sido pequeno, observouse nos com estádio IV, maior freqüência do genótipo arg/arg quando comparado aos com estádio I. Não se observou correlação entre este polimorfismo e fumo, álcool, grau de diferenciação e risco de recurrência.

Lima JM, Serafim PVP, Silva IDCG, Forones NM. Role of the genetic polymorphism of p53 (codon 72) gene in colorectal cancer. Arq Gastroenterol. 2006;43(1):8-13.

ABSTRACT - Background - Polymorphisms are genetic variations that can occur in sequences of codons, leading to defective proteins. p53 is the most commonly gene affected in human cancer. The polymorphism of this gene occurs by a substitution of a base in codon 72 and may increase the risk of cancer. Aim - To investigate the possible association between p53 arginine/72 proline polymorphism and susceptibility to colorectal cancer. Patients and Methods - This polymorphism was studied by polymerization chain reaction using specific primers in 100 patients with colorectal cancer paired by sex and age to 100 patients without cancer. Alcohol and tobacco used by all the patients and clinical aspects as stage, grade of differentiation and recurrence in the case group was compared with the genotype analyzed. Results - The frequency of homozygosis for arginine was $56 \%$ in the cancer group and $58 \%$ in the control group. No significant difference was observed among both groups. This genotype was more frequent in colorectal cancer patients stage IV than in stage I ( $80 \%$ versus $14 \%)$. There was no significant difference between genotypes and alcohol, tobacco, grade of differentiation or recurrence. Conclusion - Homozygosity for arginine was the most prevalent genotype in both groups. The frequency of codon 72 proline/arginine p53 gene polymorphism was not correlated with a higher risk of colorectal cancer. Arginine/arginine genotype was more prevalent in advanced cancer patients (stage IV).

HEADINGS - Polymorphism (genetics). Genes, p53. Colorectal neoplasms. Prognosis. 


\section{REFERÊNCIAS BIBLIOGRÁFICAS}

1. Brasileiro-Filho G, Guimarães RC, Bogliolo L. Distúrbios do crescimento e da diferenciação celular. In: Brasileiro-Filho G, editor. Patologia clínica. Rio de Janeiro: Guanabara Koogan; 1998. p.148-92.

2. Brose MS, Smyrk T, Weber B, Lynch HT. Genetic predisposition to cancer - cancer etiology. In: Bast RC Jr, Kufe DW, Pollock RE, Weichselbaum RR, Holland JF, Frei E, editors. Cancer medicine. Ontario, Canada: BC Becker; 2000. p.168-84.

3. Cotti GCC, Santos FPS, Sebastianes FM, Habr-Gama A, Seid VE, Martino RB Genética do câncer colorretal. Rev Med. (São Paulo) 2000;79:45-64.

4. Gemignani F, Moreno V, Landi S, Moullan N, Chabrier A, Gutiérrez-Enríquez S, Hall J, Guino E, Peinado MA, Capella G, Canzian F. A TP53 polymorphism is associated with increased risk of colorectal cancer and with reduced levels of TP53 mRNA. Oncogene. 2004;23:1954-6.

5. Gomes DC, Oliveira JFP, Duarte KS, Santos MO, Rebelo MS, Reis RS. Estimativas da incidência e mortalidade por câncer no Brasil. Ministério da Saúde. Instituto Nacional de Câncer (INCA). Site: http://www.inca.gov.br/ 01/2005.

6. Greenblatt MS, Bennett WP, Hollstein M, Harris CC. Mutations in the p53 tumor suppressor gene: clues to cancer etiology and molecular pathogenesis. Cancer Res. 1994;54:4855-78.

7. Harris CC, Hollstein M. Clinical implication of the p53 tumor suppressor gene. N Engl J Med. 1993;329:318-27.

8. Kietthubthew S, Sriplung H, Au WWW, Ishida T. The p 53 codon 72 polymorphism and risk of oral cancer in southern Thailand. Asian Pac J Cancer Prev. 2003;4:209-14.

9. Lane DP. Cancer. p53, guardian of the genome. Nature. 1992;358:15-6.

10. Langerod A, Bukholm IR, Bregard A, Lonning PE, Andersen TI, Rognum TO, Meling GI, Lothe RA, Borresen-Dale AL. The TP53 codon 72 polymorphism may affect the function of TP53 mutations in breast carcinomas but not in colorectal carcinomas. Cancer Epidemiol Biomarkers Prev. 2002;11:1684-8.

11. Lodish H, Berk A, Zipursky SL, Matsudaira P, Baltimore D, Darnell J. Análise genética em biologia molecular. In: Nader HB, editor. Biologia celular e molecular. Rio de Janeiro: Revinter; 2002. p.255-93.

12. Lynch HT, Lynch JF. Genetics of colonic cancer. Digestion. 1998;59:481-92.

13. Marin MC, Jost CA, Brooks LA, Irwin MS, O’Nions J, Tidy JA, James N, McGregor JM, Harwood CA; Yulug IG, Vousden KH, Allday MJ, Gusterson B, Ikawa S, Hinds PW, Crook T, Kaelin WG. A common polymorphism acts as an intragenic modifier of mutant p53 behaviour. Nat Genet. 2000;25:47-54

14. National Center for Biotechnology Information. Site: www.ncbi.nlm.nih.gov/ $\mathrm{jan} / 2005$
15. Nussbaum RL, McInnes RR, Willard HF. Variação genética em indivíduos: mutação e polimorfismo. In: Motta PA, editor. Genética médica. Rio de Janeiro: Guanabara Koogan; 2002. p.69-82.

16. Papadakis ED, Soulitzis N, Spandidos DA. Association of p53 codon 72 polymorphism with advanced lung cancer: the Arg allele is preferentially retained in tumours arising in Arg/Pro germline heterozygotes. Br J Cancer. 2002;87:1013-8.

17. Papadakis EN, Dokianakis DN, Spandidos DA. p53 codon 72 polymorphism as risk factor in the development of breast cancer. Mol Cell Biol. 2000;3:389-92.

18. Sayhan N, Yazici H, Budak M, Dalay N. p53 codon 72 genotypes in colon cancer. Association with human papillomavirus infection. Res Commun Mol Pathol Pharmacol. 2001;109:25-34.

19. Schneider-Stock R, Boltze C, Peters B, Szibor R, Landt O, Meyer F, Roessner A. Selective loss of codon 72 proline p53 and frequent mutational inactivation of the retained arginine allele in colorectal cancer. Neoplasia. 2004;6:529-35.

20. Shaw P, Bovey R, Tardy S, Sahli R, Sordat B, Costa J. Induction of apoptosis by wild type p53 in a human colon tumor-derived cell-line. Proc Natl Acad Sci USA 1992;89:4495-9.

21. Smith ML, Fornace AJ Jr. The two faces of tumor suppressor p53. Am J Pathol. 1996;148:1092-100

22. Soulitzis N, Sourvinos G, Dokianakis DN, Spandidos DA. p53 codon 72 polymorphisms and its association with bladder cancer. Cancer Lett. 2002;179:175-83.

23. Tada M, Furuuchi K, Kaneda M, Matsumoto J, Takahashi M, Hirai A, Mitsumoto Y, Iggo $\mathrm{RD}$, Moriuchi T. Inactivate the remaining p53 allele or the alternate p73? Preferentia selection on the $\operatorname{Arg} 72$ polymorphism in cancers with recessive $\mathrm{p} 53$ mutants but not transdominant mutants. Carcinogenesis. 2001;22:515-7.

24. Thomas M, Kalita A, Labrecque S, Pim D, Banks L, Matlashewski G. Two polymorphic variants of wild-type p53 differ biochemically and biologically. Mol Cel Biol. 1999;19:1325-8.

25. Vogelstein B, Fearon ER, Kern SE, Hamilton SR, Preisinger AC, Nakamura Y, White R. Allelotype of colorectal carcinomas. Science. 1989;244:207-11.

26. Xiong Y. p21 is a universal inhibi for of cyclina kinases. Nature. 1993;366:701-4

27. Yamaguschi MD, Sugano K, Fukayama N, Nakashima Y, Saotome K, Yokoayama T, Yokota T, Ohkura H. Polymerase chain reaction-based approaches for detection of allelic loss in the p53 tumor suppressor gene in colon neoplasms. Am J Gastroenterol. 1997;92:307-12. 